\title{
Integration of Upper Division Business Core Classes: A Lesson in Informing Science
}

\author{
John D. Haney and Mary Bowers \\ Northern Arizona University, Flagstaff, AZ, USA
}

Oohn.haney@nau.edu, mary.bowers@nau.edu

\begin{abstract}
In an effort to provide knowledge and skills essential for successful careers, the College of Business Administration (CBA) designed and offered a course in Fall 2000 consisting of four classes (marketing, management, computer information systems, and business communication) taught together in a block by a faculty team. The overarching goal of this course format was to present business as an interdisciplinary process, to link concepts to practice. The course was named BizBlock. The BizBlock experiment for the 2000-2001 academic year showed that misinformation that leads to unfulfilled expectations results in general student dissatisfaction. The imbalance and lack of integration among the four disciplines contributed to high dissatisfaction based on unfulfilled student expectations. The results of student feedback regarding BizBlock indicate that when properly informed, people consider even an unsatisfactory experience acceptable if it is what was expected.
\end{abstract}

Keywords: Informing Science, Business Core, Cross-Functional Teaching

\section{Introduction}

\section{Course Description}

BizBlock combined four core business classes: marketing, management, computer information systems, and business communication. This configuration of classes was selected because of the inherent overlap between marketing and management. The communication and computer systems components were added as overlays necessary to effectively support marketing and management practices. Students formed teams and used what they learned in marketing and management to create a comprehensive business plan, start and run a business, and effectively manage group performance. The communication component of the class provided students with relevant professional writing and presentation skills while computer systems focused on the development of an e-business eb site. The curriculum was developed using the case study approach to help students better understand concepts and to refine their writing skills. The case studies also allowed students to better formulate their business plan and to anticipate and solve problems that might occur during the start-up and progress of their business.

Material published as part of these proceedings, either on-line or in print, is copyrighted by Informing Science. Permission to make digital or paper copy of part or all of these works for personal or classroom use is granted without fee provided that the copies are not made or distributed for profit or commercial advantage AND that copies 1) bear this notice in full and 2) give the full citation on the first page. It is permissible to abstract these works so long as credit is given. To copy in all other cases or to republish or to post on a server or to redistribute to lists requires specific permission from the publisher at Publister@intormingscience.org

\section{Catalog description}

Undergraduate core introduction to marketing, management, communications, and information systems, fulfills the requirement for MKT 333, MGT 300, BA 350, CIS 360, and the junior level writing requirement. 
Integration of Upper Division Business Core Classes

\section{Flyer description}

See Appendix I.

\section{Students Enrolled}

Students who have just received business major status (see Appendix II - which will be the catalog page describing requirements for admission into the College of Business) or who are just beginning to take their core business courses comprised the majority of BizBlock students. There were several pre-MBA students enrolled in BizBlock who did not receive an undergraduate degree in business or received a business degree from a foreign institution who enrolled in BizBlock to satisfy MBA admission requirements.

Students received information about BizBlock either during Previews (an orientation program that provides information about the College and class registration), via the Academic Advising Center, or by reading flyers that were heavily distributed and posted throughout the CBA building. Because it was a new course, there were no previous students and hence no student-to-student feedback and advice regarding BizBlock.

Students who were presented with this information formed two primary expectations:

- they would do 9 credits worth of work and receive 12 credits

- they would receive an integrated learning experience

Fall 2000 enrollment totaled 58 students.

\section{Credit and Class Hours}

Students would be taking four classes that if taken separately would total 12 credit hours or 12 class hours per week. Because of the integration of business communication and computer information systems into one collective grade, class time was scheduled proportionately:

Management and Marketing: Monday and Wednesday 9:00 - 12:00

Communication and Information Systems Friday 9:00 - 12:00

As such, the BizBlock resulted in 9 class hours per week.

\section{Expected Outcomes}

BizBlock would fulfill the upper division requirement of Management and Marketing. Students would receive three (3) credit hours and a grade in each of these two courses. In addition, completing the block would waive the Business Communication and Information Systems requirements; however, no specific grade would be assigned for the courses but rather would be combined into a BA 399 grade. This waiver did not reduce the number of hours for graduation.

The student would then have three credit hours to be used for an upper division elective. Therefore, BizBlock would appear as 9 credit hours on a student transcript: 3 credit hours each for Management and Marketing and 3 credit hours for a composite course, consisting of Business Communications and Information Systems.

As stated earlier, from the process and manner in which students were informed, their expectations regarding outcomes would be that they would take four courses but only devote three class hours to this course. While not stated explicitly in any BizBlock descriptions (flyers or the catalog), how students came to this understanding regarding the credit hours and workload is understandable. Moreover, the course 
information clearly presents BizBlock as an integrated, balanced curriculum. Students had no reason to anticipate otherwise.

\section{Student Feedback Regarding Outcomes - Fall Semester}

Due to the experimental nature of the course and that Fall 2000 was the first time the course was offered, college administration (particularly the curriculum committee) was highly invested in student feedback. Not only were standard individual faculty evaluations administered but also an additional survey in questionnaire format (by the authors) was distributed via e-mail and the curriculum committee conducted a focus group. While individual faculty evaluations are confidential, the summarized results of the other assessments are presented.

\section{Author Survey Questionnaire}

See Appendix III.

\section{Responses concerning Balance among Courses}

Question 2: The content of the four areas was integrated.

Question 4: The percentage coverage of management in the class was about:

Question 5: The percentage coverage of marketing in the class was about:

Question 6: The percentage coverage of computer information systems presented in the class was about:

Question 7: The percentage coverage of business communications presented in the class was about:

The overall average for Question 2, on a scale of 1 to 10, was 5. This indicates that students did not believe there was an appropriate balance between the four courses making up the BizBlock. This perception is supported by the responses to questions 4-7 in which students attributed percentage of time allotted to each individual class. (The "correct" response would have been: 33\% to management and marketing and $17 \%$ to CIS and Comm.) The actual results were 25\% for Management, $47 \%$ for Marketing, $13 \%$ for Business Communications, and 16\% for Information Systems.

What the students expected, based on how they were informed, was an integrated, balanced, experience of the content of the four courses. What the students encountered was a non-integrated, unbalanced experience. Was this because they were improperly informed or because the implementation of the course did not match the information?

In the case of balance, the students' experience truly was a result of improper implementation because of the greater workload in one discipline. This is the only variable that would account for the student responses since the class time was appropriately balanced.

The lack of integration was due primarily to the way the class time was configured with Management and Marketing meeting on Monday and Wednesday, and Business Communications and Information Systems meeting on Fridays.

The result was that what the students were informed about the course and what they experienced did not match. 
Integration of Upper Division Business Core Classes

\section{Responses Concerning Student Expectation and Experience}

Question 8: Overall the class was equivalent to what you anticipated.

Question 11: How did your experience in the class match the description of the class as stated in the first paragraph of this questionnaire?

Question 3: The workload of the class was equivalent to 9 credits.

Responses to questions 8 and 11 further support the fact that students' expectations of what the class was going to be like and what the class actually provided were fairly disparate and negative. On a scale of 1 to 10, the average for Question 8 was 4, and the average for Question 11 was 4.6. Responses to question 3 indicate students believed they did more that nine credit hours' worth of work. This is the area of highest student discontent. Based on the information they received they truly believed they would receive 12 credits for doing 9 credits worth of work. The actual experience was 9 credits for 12 or more credits worth of work. And, based on the results of Questions 4-7 as shown above, the overload was primarily in one discipline. (This assumption is supported by the focus group results presented in the next section.)

\section{Responses Concerning Student Satisfaction}

Question 9: Knowing before hand what you know now, would you take this class?

Question 10: Would you recommend this class to a friend?

Responses to question 9 and 10 reflect student satisfaction with the course. Since most students surveyed indicated they would not take the course again (2.5 on a scale of 1 to 10) or recommend the course to a friend (2.7 on a scale of 1 to 10$)$, it is reasonable to assume a fairly high degree of dissatisfaction. More specific reasons for their dissatisfaction have been alluded to (credit hours and lack of balance) and will be presented more clearly in the section regarding the focus group.

Overall, the survey results suggest there was a significant disconnect between the course as it was promoted and the course as it was actually implemented.

For a complete presentation of the Fall 2000 author survey results, see Appendix IV.

\section{Survey Comments}

I think we should receive all 12 credits. Class would have been better if they would have lectured the first part of the semester and then started this business.

I like the statement of "Learn by doing" but I would like some instruction before I tackle a project that is equivalent to $10 \%$ of my grade.

Well, where do I start! I would need another page to fully explain my disinterest for this block.

This class was supposed to be integrated but I found that most of the class time and projects were in marketing. If I were a marketing major it would be cool but I am not so the class was a joke. The assignments we had to do were much more than 9 credits worth and some of the assignments had nothing to do with what we were doing in class.

The class is a great concept, however it has a lot of things to work out. The time was not distributed evenly between the 4 classes. Marketing had at least 50\% of the class time, maybe more.

The most frustrating aspect of this course for me was that I felt the things that required the most time on 
my part (relating to the SBU) I was not rewarded for with points. These were by far the most demanding nine credits I have earned at NAU.

The workload was more than 9 credit hours. The class was unorganized [...].

For the amount I have done, 12-15 credit hours should be awarded.

The workload was outrageous! We did the work of five classes ( $m k t, m g t$, cis, comm, and a class business) and only received nine credit hours.

The idea of combined course is very interesting but it needs a lot of work, especially from the instructors. They have to compile a balanced schedule so that class work and home assignments of all four courses would be equally emphasized. Professors need to discuss it before hand, agree on a schedule and not change it at the last moment. If this preliminary work is not done, one of the instructors will put tremendous load on students simply to keep them busy with one course, and become a leading instructor for the combined course, In BizBlock it happened with Marketing, where students had all their efforts. It seemed as, instead of working for 9 hours to complete 4 classes, students worked 25 hours for just one class.

\section{Focus Group Results}

The Focus Group results support the survey results of the authors. The primary question, If you had to do it again, would you? provided the following results: 8 -yes; 32- no.

Some of the summarized and selected responses from the Focus Group are:

Would take the course again if it was worth more credits (many students thought it was a 12 credit hour class).

Too much time commitment for 9 credit hours.

More IS and comm. needed. Content needed to be more balanced between courses.

Unorganized; didn't followed syllabus.

Starting a business and doing all the coursework at the same time was too much to do in one semester.

\section{Student Feedback Regarding BizBlock - Spring Semester}

All the feedback regarding BizBlock was not negative. Nonetheless, near mid-semester it became apparent there was considerable student dissatisfaction with the course.

Also at mid-semester, students began registering for spring semester. As registration progressed, the enrollment for BizBlock remained low. To boost this low enrollment, a new flyer was designed and was quickly distributed and posted. (See Appendix V) In addition, a CBA administrator and several BizBlock faculty members made brief presentations about BizBlock in various business classes. Part of the presentation was to (as candidly as possible) address the negative word of mouth communication regarding BizBlock.

During spring registration, students received information regarding BizBlock from the same sources as in the fall: Previews, Advising Center, and flyers. However, the flyer was different and additional sources of information included class presentations and student feedback. While the effect of each form of information cannot be quantifiably ascertained, it appears negative student feedback (as reflected in the surveys and focus group) was highly influential. Enrollment for BizBlock in spring semester totaled only 32 students. 
Integration of Upper Division Business Core Classes

It should be noted that the only real change in the course itself between fall and spring semesters was the replacement of the faculty member teaching management. This change was a result of a sabbatical leave. The class schedule and assignments were basically unchanged.

\section{Responses Concerning Balance among Courses}

The identical questionnaire administered during the fall semester was again given during the spring semester.

Question 2: The content of the four areas was integrated.

Question 4: The percentage coverage of management in the class was about:

Question 5: The percentage coverage of marketing in the class was about:

Question 6: The percentage coverage of computer information systems presented in the class was about:

Question 7: The percentage coverage of business communications presented in the class was about:

Responses to Question 2 indicate that students in the spring perceived a slightly better balance between the courses (6.25 as compared to 4.0). The balance of the workload, as reflected in Questions 4-7, still do not accurately reflect the actual allotment; students saw the time used by Management, Business Communications, and Information Systems as being fairly close (22\%, 18\%, and $18 \%$ respectively). While the percent of Marketing was not seen as great as it was in the fall, $(46 \%$ v. $42 \%)$ it was still viewed as the dominant course.

\section{Responses Concerning Student Expectation and Experience}

Question 3: The workload of the class was equivalent to 9 credits.

Question 8: Overall the class was equivalent to what you anticipated.

Question 11: How did your experience in the class match the description of the class as stated in the first paragraph of this questionnaire?

The responses to questions 8 and 11 are noteworthy particularly in respect to the responses to the same questions made by students in the fall (Question 8 -4.0, Question $11-4.57$ ). The responses in the spring (Question 8-6.25, Question $11-7.13$ ) indicate that students' expectations of the class were closer to their actual class experience. It can be inferred from the average response score to Question 3 that many students still believed the work done and credit received were not equal. However, the number of students who believed this inequality existed decreased from fall to spring (3.9 vs. 5.75). Given the results of Questions 4-7, the results of Question 3 are problematic. Since the workload in fall was similar to the workload in spring it would be expected that the responses to Question 3 between fall and spring would be more comparable. One possible conclusion is that even though the workload was similar, the information the students received from their peers from the fall class established their expectations and was more reflective of the course.

\section{Responses Concerning Student Satisfaction}

Question 9: Knowing before hand what you know now, would you take this class?

Question 10: Would you recommend this class to a friend? 
From the considerably more positive average responses to questions 9 and 10, it can be assumed that student satisfaction with BizBlock was greater in the spring semester (question 9 - 7.13; question 10 - 6.50) than it was in the fall semester (question 9-2.48; question $10-2.71$ ).

For a complete presentation of the Spring 2001 author survey results, see Appendix VI.

\section{Survey Comments}

The BizBlock I class did integrate the classes listed in the description but course material was not evenly presented. Most of the class was focused on marketing, then management, CIS, and business communication.

This class requires a lot of outside class time attention. Assignments do not correlate with the project of the class.

There was just not enough emphasis on the e-commerce "Learn by doing!"

The concept was very effective. We received hands on experience on starting a business which give us an advantage above and beyond people who haven't. I wouldn't recommend the class to a friend because of the amount of time and effort required for the class. On top of that, the grades are average. Basically, I don't think we will receive the grade that we worked for.

There was no focus group conducted in the spring.

\section{Discussion}

Was the greater student satisfaction in the spring attributable to their being better informed or to the changes in the course?

\section{Better Informed}

Were the spring semester students actually better informed? Yes, if better is defined as more accurate. They received the same amount of formal (CBA sanctioned) information: Previews, the Advising Center, and the flyers. They also received additional formal information via presentations made to various classes by administrators and BizBlock faculty. However, spring semester students received informal (word of mouth from students who took BizBlock in the fall) information that was not previously available. While difficult to quantifiably assess, it appears that both the amount and the quality of the information received by spring students was a positive influence on their overall satisfaction with the course. Strictly speaking, the more accurate description of BizBlock provided in the class presentations and flyers may have had some impact. However, the description of the BizBlock by students who took the course, while negative, helped spring semester students form more realistic expectations. In other words, spring semester students had a preconceived notion going into the class that it would be hell; any experience better than hell was perceived as positive.

\section{Change in the Course}

Again, the basic requirements of the course remained the same; students were responsible for writing case studies, taking exams, selecting a business, formulating a business plan, creating a web site, starting and managing the business, and presenting the results of their business to current BizBlock students and faculty.

The only difference between fall and spring semester was the replacement of the faculty member teaching the management section of the course. This was due to the original faculty member going on sabbatical 
leave in December. Anecdotally, students did not evaluate the spring semester management professor higher than the fall semester professor. Therefore, it would be difficult to assume this change resulted in greater student satisfaction with the course.

\section{Conclusions}

The experience of the BizBlock experiment shows that misinformation which leads to unfulfilled expectations results in general student dissatisfaction. The fact that most students, based on the information they had received, truly believed they would receive twelve credits for doing nine credits worth of work. When it became apparent they were going to receive nine credits for doing the workload of twelve credits or more, the level of dissatisfaction rose significantly. The overload was in one discipline and when no effort was made to lessen the overload, the dissatisfaction remained high. This imbalance and lack of integration among the four disciplines also contributed to high dissatisfaction based on unfulfilled expectations. This study also shows that when people are properly informed, they perceive even an unpleasant experience as satisfactory if it was what was expected.

Information is not merely a function of delivery or amount. It is most influential, has the most impact when it is correct and timely. There is a strong link between accurate information, realistic expectations, and satisfaction.

\section{References}

Michaelsen, L. K. (1999). An intensive, hands-on experience to integrate the core business curriculum. Selections, Winter, 9-14. 


\section{Appendix I}

\section{Business Students! Stop jumping thru hoops!}

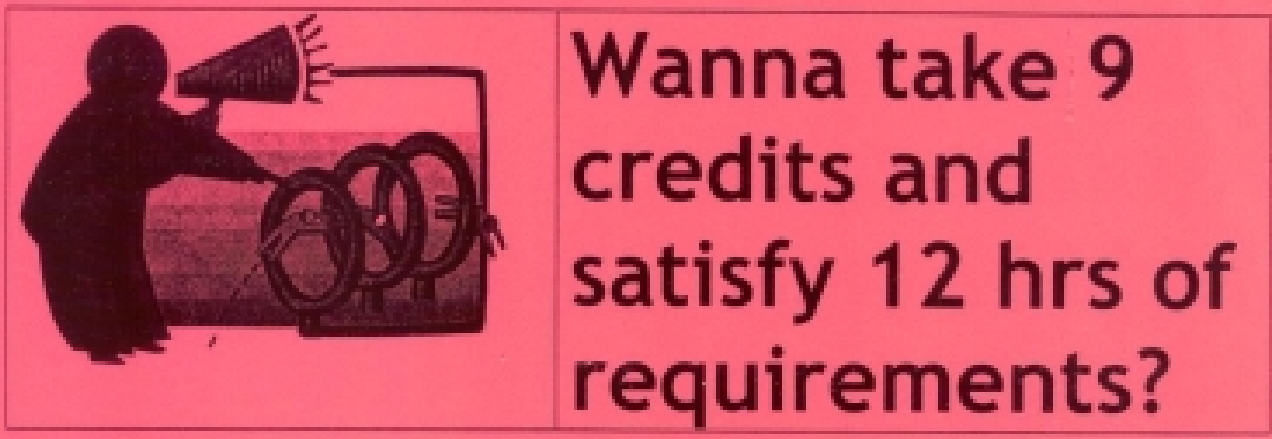

\section{New Integrated Classes: Business Block 1}

- A 9-unit block of classes that satisfies requirements for 12 units!

- Material from Management, Marketing, Computer Information Systems and Business Communications is integrated into a business block over the entire semester.

- Complete all of these courses with a set of students, consistent teams, and coordinated instructors using integrated materials to help you master business concepts. Learn by doing!

The Bottom Line: Completing this block of classes ( 9 hours) will fulfill the following upper-division business core requirements: MGT 300, MKT 333, CIS 360, and BA 350. The 3 hours saved will be used for an upper-division business elective. (This substitution does not reduce the total number of hours you need to graduate-but it gives you more flexibility in the courses you take.)

\section{How do you sign up?}

Register for the block of three classes inside one of the boxes (either 1a OR 1b) below: Remember, you must register for all three classes in the block. Enroll now!

\begin{tabular}{|c|c|c|c|c|c|}
\hline \multicolumn{6}{|c|}{ Business Block 1a: } \\
\hline Seq. No. & Course & Section & Titie & Days & Time \\
\hline 12877 & MGT 300 & 02 & Managing Behavisor & MWF & $9: 10-10: 00$ \\
\hline 12867 & BA 399 & 01 & Custamer Prioniles and Business Design & MWF & $10: 20 \cdot 11: 10$ \\
\hline 12881 & NKT 333 & 03 & Intro to Warketing & MWF & $11: 30 \cdot 12: 20$ \\
\hline \multicolumn{6}{|c|}{ Business Block 1b: } \\
\hline Seq. No. & Course & Section & Titie & Days & Time \\
\hline 12800 & MKT 330 & 01 & Intro to Marketing & WWF & $9: 10-10: 00$ \\
\hline 12869 & 84599 & Q2 & Customer Priorities and lusiness Design & MWF & $10: 20-11: 10$ \\
\hline 12878 & MGT 300 & 03 & Manhying Benavior & MWF & $11: 30-12-20$ \\
\hline
\end{tabular}

(Coming in Spring 2001...the rest of the story...Dusiness Block 2...stay tunedl) 


\section{Appendix II}

Registration Policy for 300-400 Level Business Courses - College of Business Administration 19952001.

\section{The Business Undeclared Program}

Each student, including transfer students, admitted to the College of Business Administration will initially be classified as a business undeclared student. The student will follow the Business Undeclared program (freshman-sophomore) sequence of course in completing the prescribed English, math and lower-division Business Core courses in preparation for the professional business program (junior-senior). Business Undeclared students will not be allowed to register for 300/.4000-level business course. (Exceptions to this policy are: BA305, BA350m and upper-division economics courses.)

\section{The Professional Business Program}

In general the junior-senior years constitute the professional program of the undergraduate curriculum. The following standards are required for admission to Business Major Status:

1. Completion of at least 567 credit hours with a minimum overall grade point average of 2.00

2. Completion of ENG 101:102 or ENG 105, MAT 110:119, CIS 120, ACC 255:256, BA 201:205, ECO 284:285, with a minimum overall grade point average for these courses of 2.75 and a grade of "C" or better in each of these courses.

\section{Appendix III \\ Business Block I Questionnaire}

The advertisement for the Business Block I class states:

A 9-unit block of classes that satisfies requirements for 12 units! Material from Management, Marketing, Computer Information Systems and Business Communications is integrated into a business block over the entire semester. Complete all of these courses with a set of students, consistent teams, and coordinated instructors using integrated materials to help you master business concepts. Learn by doing! Completing this block of classes ( 9 hours) will fulfill the following upper-division business core requirements: MGT 300, MKT 333, CIS 360, and BA350.

On a scale of 1 to 10, (10 being the highest) please rate the following questions:

1) The BizBlock class was a balance of the four courses listed above.

\begin{tabular}{|l|l|l|l|l|l|l|l|l|l|}
\hline 10 & 9 & 8 & 7 & 6 & 5 & 4 & 3 & 2 & 1 \\
\hline
\end{tabular}

2) The content of the four areas was integrated.

\begin{tabular}{|l|l|l|l|l|l|l|l|l|l|}
\hline 10 & 9 & 8 & 7 & 6 & 5 & 4 & 3 & 2 & 1 \\
\hline
\end{tabular}

Integrated

Not Integrated 
3) The workload of the class was equivalent to 9 credits.

\begin{tabular}{|l|l|l|l|l|l|l|l|l|l|}
\hline 10 & 9 & 8 & 7 & 6 & 5 & 4 & 3 & 2 & 1 \\
\hline
\end{tabular}

Equivalent

Not Equivalent

4) The percentage coverage of management presented in the class was about:

\begin{tabular}{|l|l|l|l|l|l|l|l|l|l|}
\hline 100 & 90 & 80 & 70 & 60 & 50 & 40 & 30 & 20 & 10 \\
\hline
\end{tabular}

5) The percentage coverage of marketing presented in the class was about:

\begin{tabular}{|l|l|l|l|l|l|l|l|l|l|}
\hline 100 & 90 & 80 & 70 & 60 & 50 & 40 & 30 & 20 & 10 \\
\hline
\end{tabular}

6) The percentage coverage of Computer Information Systems presented in the class was about:

\begin{tabular}{|l|l|l|l|l|l|l|l|l|l|}
\hline 100 & 90 & 80 & 70 & 60 & 50 & 40 & 30 & 20 & 10 \\
\hline
\end{tabular}

7) The percentage coverage of Business Communications presented in the class was about:

\begin{tabular}{|l|l|l|l|l|l|l|l|l|l|}
\hline 100 & 90 & 80 & 70 & 60 & 50 & 40 & 30 & 20 & 10 \\
\hline
\end{tabular}

8) Overall the class was equivalent to what you anticipated.

\begin{tabular}{|l|l|l|l|l|l|l|l|l|l|}
\hline 10 & 9 & 8 & 7 & 6 & 5 & 4 & 3 & 2 & 1 \\
\hline
\end{tabular}

Equivalent Not Equivalent

9) Knowing before hand what you know now, would you take the class?

\begin{tabular}{|l|l|l|l|l|l|l|l|l|l|}
\hline 10 & 9 & 8 & 7 & 6 & 5 & 4 & 3 & 2 & 1 \\
\hline
\end{tabular}

Yes

No

10) Would you recommend this class to a friend?

\begin{tabular}{|l|l|l|l|l|l|l|l|l|l|}
\hline 10 & 9 & 8 & 7 & 6 & 5 & 4 & 3 & 2 & 1 \\
\hline
\end{tabular}

11) How did your experience in the class match the description of the class as stated in the first paragraph of this questionnaire?

\begin{tabular}{|l|l|l|l|l|l|l|l|l|l|}
\hline 10 & 9 & 8 & 7 & 6 & 5 & 4 & 3 & 2 & 1 \\
\hline
\end{tabular}

Equivalent

Not Equivalent

Comments: 
Integration of Upper Division Business Core Classes

\section{Appendix IV}

\section{Business Block I Questionnaire - Fall 2000 Questions}

$\begin{array}{llllllllllll}\mathbf{1} & \mathbf{2} & \mathbf{3} & \mathbf{4} & \mathbf{5} & \mathbf{6} & \mathbf{7} & \mathbf{8} & \mathbf{9} & \mathbf{1 0} & \mathbf{1 1} & \\ 3 & 4 & 1 & 50 & 80 & 40 & 40 & 5 & 4 & 5 & 6 & \\ 2 & 2 & 1 & 30 & 90 & 40 & 30 & 2 & 3 & 3 & 2 & \\ 4 & 7 & 10 & 20 & 60 & 10 & 10 & 3 & 2 & 1 & 5 & \\ 8 & 7 & 1 & 40 & 40 & 10 & 10 & 10 & 1 & 1 & 10 & \\ 1 & 1 & 2 & 20 & 30 & 40 & 10 & 1 & 1 & 1 & 2 & \\ 5 & 6 & 6 & 20 & 50 & 10 & 20 & 5 & 1 & 1 & 3 & \\ 5 & 4 & 1 & 30 & 50 & 10 & 10 & 1 & 1 & 1 & 3 & \\ 5 & 5 & 3 & 20 & 60 & 10 & 10 & 4 & 1 & 1 & 4 & \\ 5 & 9 & 3 & 30 & 30 & 10 & 30 & 4 & 4 & 5 & 7 & \\ 6 & 6 & 1 & 30 & 50 & 10 & 10 & 4 & 1 & 1 & 7 & \\ 2 & 4 & 4 & 40 & 80 & 20 & 20 & 4 & 3 & 3 & 4 & \\ 3 & 3 & 5 & 20 & 60 & 10 & 10 & 3 & 2 & 2 & 2 & \\ 7 & 6 & 5 & 30 & 50 & 10 & 10 & 6 & 1 & 4 & 6 & \\ 4 & 6 & 5 & 30 & 40 & 10 & 20 & 4 & 3 & 4 & 5 & \\ 2 & 3 & 1 & 30 & 70 & 10 & 20 & 2 & 2 & 2 & 3 & \\ 1 & 6 & 10 & 30 & 40 & 20 & 10 & 4 & 1 & 1 & 2 & \\ 3 & 5 & 1 & 30 & 40 & 10 & 20 & 3 & 1 & 1 & 4 & \\ 8 & 7 & 9 & 60 & 90 & 30 & 50 & 7 & 9 & 9 & 8 & \\ 3 & 5 & 10 & 10 & 60 & 10 & 20 & 6 & 8 & 7 & 6 & \\ 5 & 4 & 2 & 30 & 40 & 10 & 20 & 4 & 2 & 3 & 2 & \\ 2 & 5 & 1 & 20 & 50 & 10 & 20 & 2 & 1 & 1 & 5 & \\ & & & & & & & & & & & \\ 4.00 & 5.00 & 3.90 & 29.52 & 55.24 & 16.19 & 19.05 & 4.00 & 2.48 & 2.71 & 4.57 & \text { Avg } \\ 8.00 & 9.00 & 10.00 & 60.00 & 90.00 & 40.00 & 50.00 & 10.00 & 9.00 & 9.00 & 10.00 & \text { Max } \\ 1.00 & 1.00 & 1.00 & 10.00 & 30.00 & 10.00 & 10.00 & 1.00 & 1.00 & 1.00 & 2.00 & \text { Min }\end{array}$




\section{Appendix V}

\section{LEARN MORE - EARN MOREIII}

\section{Learn the latest business skills AND how to use them!!}

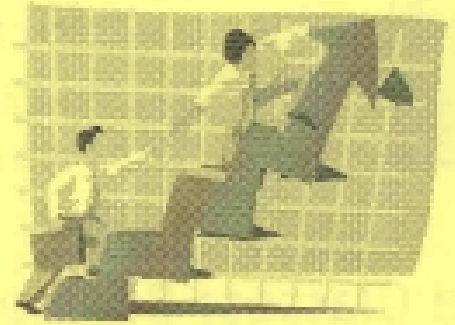

\section{Take 9 credits and fill 12 hours of requirements}

BUSINESS BLOCK 1 is an integrated 9 -credt course that combines:

- Important business management, marketing. communication, and computer concepts with the hands-on experience of running a real company.

BUSINESS BLOCK 1 is an innovative course that emphasizes:

- Interactive learring

- Group work

- E-commerce and web applications

- Team teaching

BUSINESS BLOCK 1 wil fulfil the following upper-dvision business care requirements: MGT 300, MIKT 333, CIS 380 , and BA 350. The 3 heurs saved can be used for an upperdivision business elective (This substitution does not reduce the total number of business credit hours needed to graduate)

\section{TO REGISTER:}

Select ONE of the sequence numbers in the bax below

\section{Business Block I:}

\begin{tabular}{|c|l|c|c|}
\hline Seq. No. & Title & Days & Time \\
\hline 19052 & Business Block I - BA 399 & MWF & $9: 10-$ \\
or & Fills requirements for MGT 300,MKT 333, CIS & & $12: 00$ \\
19054 & 360, BA 350 & & \\
\hline
\end{tabular}

Register today! 
Integration of Upper Division Business Core Classes

\section{Appendix VI}

\section{Business Block I Questionnaire - Spring 2001 Questions}

$\begin{array}{llllllllllll}\mathbf{1} & \mathbf{2} & \mathbf{3} & \mathbf{4} & \mathbf{5} & \mathbf{6} & \mathbf{7} & \mathbf{8} & \mathbf{9} & \mathbf{1 0} & \mathbf{1 1} & \\ 7 & 7 & 5 & 40 & 70 & 50 & 50 & 5 & 10 & 10 & 7 & \\ 10 & 8 & 4 & 20 & 60 & 10 & 10 & 7 & 7 & 4 & 8 & \\ 3 & 8 & 8 & 30 & 50 & 10 & 10 & 9 & 7 & 8 & 9 & \\ 6 & 9 & 10 & 80 & 90 & 70 & 80 & 9 & 10 & 10 & 10 & \\ 4 & 5 & 3 & 60 & 90 & 50 & 50 & 5 & 5 & 5 & 5 & \\ 3 & 4 & 7 & 20 & 40 & 20 & 20 & 3 & 1 & 1 & 3 & \\ 10 & 8 & 4 & 20 & 60 & 10 & 10 & 7 & 7 & 4 & 8 & \\ 7 & 7 & 5 & 40 & 70 & 50 & 50 & 5 & 10 & 10 & 7 & \\ & & & & & & & & & & & \\ 6.25 & 7.00 & 5.75 & 38.75 & 66.25 & 33.75 & 35.00 & 6.25 & 7.13 & 6.50 & 7.13 & \text { Avg } \\ 10.00 & 9.00 & 10.00 & 80.00 & 90.00 & 70.00 & 80.00 & 9.00 & 10.00 & 10.00 & 10.00 & \text { Max } \\ 3.00 & 4.00 & 3.00 & 20.00 & 40.00 & 10.00 & 10.00 & 3.00 & 1.00 & 1.00 & 3.00 & \text { Min }\end{array}$

